\title{
Card displacement response as affected by neocortical, cerebellar, and limbic forebrain lesions in the rat
}

\author{
ROBERT THOMPSON \\ Louisiana State University, Baton Rouge, Louisiana 70803
}

\begin{abstract}
Rats previously trained to push aside a stimulus card in order to gain entrance into an area of safety showed a marked impairment of the habit following lesions to either the fronto-parietal cortex or the anterior cingulate cortex. No deficit in the card displacement habit was observed in rats sustaining either occipito-temporal, cerebellar, posterior cingulate, amygdaloid, septal, or hippocampal lesions.
\end{abstract}

In connection with a long series of lesion studies on the retention of visual discrimination habits motivated by escape from footshock (Thompson, 1976a), I observed that some rats with bilateral injuries to certain restricted regions of the brain showed a profound disturbance in the performance of a simple movement learned within the context of the discrimination situation, namely, the pushing aside of a stimulus card in order to gain access to the goalbox. ${ }^{1}$ By virtue of the high degree of localization of function prevailing for the performance of this response, a separate report of these results seemed warranted.

In the current paper, data are presented on the effects of neocortical, cerebellar, and limbic forebrain lesions on card displacement performance (CDP). In the succeeding paper (Thompson, 1976b). the effects of brainstem lesions of CDP are discussed. Since a disturbance in CDP may reflect a motivational involvement, data are also presented on the integrity of escape response performance (ERP) for all animals studied in this and the succeeding paper.

\section{METHOD}

Under the motive of escape from footshock, adult male albino rats of the $W$ istar strain were initially trained to run from the startbox, through the choice chamber, push aside a stimulus card, and enter the goalbox in a two-choice discrimination apparatus (Thompson \& Bryant, 1955). Acquisition of the card displacement response usually required from 6 to 12 trials. (Well over $90 \%$ of the rats displace the card with their nose; the remainder use their forepaws.) Training on one or more visual discrimination problems began on the following day. Since this phase of the experiment is irrelevant to the aims of the present study, a detailed description of the procedures is unnecessary (see Thompson, 1969). It is sufficient to note that the rat was required to approach an unlocked stimulus card (e.g., white) and to avoid an adjacent locked stimulus card (e.g., black), and that punishment for errors

This research was supported in part by a grant from the Graduate Council on Research, Louisiana State University. was given in the form of mild footshock. The weight of the cards with attached wooden supports ranged from 92 to $95 \mathrm{~g}$.

Following learning, most of the rats were subjected to bilateral cortical or subcortical lesions. The size of the lesions to those brain areas investigated in this report was comparable to that reported in an earlier study (Thompson, 1974). After a recovery period of 10-20 days, all rats were given a retention test which lasted from 2 to 20 days (eight trials per day), depending upon the speed with which the animal relearned the visual problem(s).

Notations of the behavior of each rat within the apparatus for the first 2 days of the retention test were used as a basis for ranking each rat on a 3-point scale for card displacement performance (CDP) and escape response performance (ERP). With respect to CDP. if the rat pushed open the card on all trials during the first 2 days (as sham operated rats invariably do), a score of 1 was recorded. On the other hand, if the rat failed to push open the card on all trials during the first 2 days (in which case the experimenter would open the door on each trial to allow the animal to enter the goalbox), a score of 3 was recorded. A score of 2 was recorded if the rat failed on some trials but succeeded on other trials to push open the card.

With respect to ERP, if the rat required no more than one series of two to three footshocks to force an escape response from the startbox on all trials during the first 2 days, a score of 1 was recorded. A score of 3 was recorded if the rat required several series of two to three footshocks to force an escape response on all trials during the first 2 days. A score of 2 was recorded if the rat occasionally required several series of two to three footshocks to force an escape response.

\section{RESULTS}

Table 1 presents the percentage of rats from each group that exhibited a disturbance (having a score above 1) in CDP and ERP. It should be noted that none of the sham operated animals showed a disturbance in CDP, and only one showed a disturbance in ERP. Neither peripheral blinding nor olfactory bulbectomy had any effect on CDP or ERP.

With respect to the neocortex, none of the 11 rats with occipito-temporal ablations exhibited a disturbance in either CDP or ERP, but a significant number of cases with fronto-parietal ablations showed a disturbance in CDP. It is important to note that this outcome is inexplicable in terms of a mass action effect: The fronto-parietal group sustained an 
Table 1

Percentage of Rats Showing a Disturbance in Card Displacement Performance (CDP) and Escape Response Performance (ERP)

\begin{tabular}{lrcc}
\hline Group & N & CDP & ERP \\
\hline Control (sham operated) & 15 & 0 & 6.7 \\
Peripheral blinding & 4 & 0 & 0 \\
Neocortex & & & \\
$\quad$ Fronto-parietal & 13 & $61.5^{*}$ & 23.1 \\
$\quad$ Occipito-temporal & 11 & 0 & 0 \\
Limbic forebrain & & & \\
$\quad$ Olfactory bulb & 4 & 0 & 0 \\
$\quad$ Anterior cingulate & 8 & $100^{*}$ & $75.0^{*}$ \\
$\quad$ Posterior cingulate & 6 & 0 & 0 \\
Amygdala & 6 & 16.7 & 33.3 \\
Septal area & 13 & 0 & 7.7 \\
$\quad$ Dorsal hippocampus & 11 & 9.1 & $45.5^{*}$ \\
$\quad$ Ventral hippocampus & 9 & 0 & 33.3 \\
Cerebellum & 6 & 0 & 16.7 \\
\hline
\end{tabular}

${ }^{*} p<.05$ (Fisher exact probability test).

average of $28.9 \%$ damage to the total neocortical surface as against $42.9 \%$ damage in the occipito-temporal group.

The only limbic forebrain area that seems to be involved in CDP is the anterior portion of the cingulate cortex.

Significant deficits in ERP appeared only in those groups having damage to, either the anterior cingulate cortex or dorsal hippocampus.

Surprisingly, no significant deficit in either CDP or ERP occurred in the cerebellectomized group.

\section{DISCUSSION}

It might be argued that the observations reported in this paper on CDP and ERP are confounded by the fact that the rats were punished for making errors on the discrimination problems. This punishment could produce an aversion not only for displacing the card. but for approaching the card as well. Such an argument is seriously weakened by the following observations: (1) Rats with lesions of either the fronto-parietal cortex, anterior cingulate cortex, or dorsal hippocampus do not make many errors in relearning visual discrimination problems (Thompson, 1976a), and yet show a deficit in CDP, ERP, or both; and (2) rats deprived of their eyes or having lesions to either the occipito-temporal cortex or lateral geniculate nuclei make many errors in relearning (or attempting to relearn) visual discriminations (Thompson, 1976a), but fail to exhibit a disturbance in CDP or ERP.
It is not clear that a motivational involvement lies at the basis of the CDP deficit. On the one hand, the groups with fronto-parietal or dorsal hippocampal lesions earned scores which suggest that a deficit in CDP is dissociable from a deficit in ERP. However, the group with anterior cingulate lesions exhibited a deficit in both CDP and ERP. Mixed findings of this sort were also obtained in the presence of lesions to various brainstem areas (Thompson, 1976b).

Using the theories of Luria (1966) and Konorski (1967) as a base, it is speculated that the CDP deficit arises from a disturbance in certain central kinesthetic mechanisms essential for the construction and monitoring of "purposive" movements in nonvisual space. Perhaps the most persuasive support for this speculation comes from the finding that virtually all of those structures involved in CDP are also involved in the performance of a maze habit (Thompson, 1974) and a vestibulo-kinesthetic discrimination habit (Thompson, 1976a). A discussion of this point is pursued in the subsequent paper (Thompson, 1976b).

\section{NOTE}

1. As far as can be determined, Rosner (1953) was the first to report that certain brain-damaged rats have an "aversion" for pushing aside a moveable door.

\section{REFERENCES}

KonoRsKI, J. Integrative activity of the brain. Chicago: University of Chicago Press, 1967.

Luria, A. R. Higher cortical functions in man. New York: Basic Books, 1966.

ROSNER, B. S. Effects of cortical lesions on maze retention by the rat. Journal of Comparative and Physiological Psychology, 1953, 46, 56-60.

Thompson, R. Localization of the "visual memory system" in the white rat. Journal of Comparative and Physiological Psychology Monograph, 1969, 69, 1-29.

Thоmpson, R. Localization of the "maze memory system" in the white rat. Physiological Psychology, 1974, 2, 1-17.

Thомpson, R. Stereotaxic mapping of brainstem areas critical for memory of visual discrimination habits in the rat. Physiological Psychology, 1976, 4, 1-10. (a)

Tномpson, R. Card displacement response as affected by brainstem lesion in the rat. Bulletin of the Psychonomic Society, 1976, 8, 103-104. (b)

Thompson, R., \& Bryant, J. H. Memory as affected by activity of the relevant receptor. Psychological Reports, 1955, 1, 393-400.

(Received for publication April 12, 1976.) 